\title{
Relationships Between Drainage Area, Slope Length, AND SLOPE GRADIENT FOR RIPARIAN SLOPES IN VIRGINIA
}

\author{
S. P. Inamdar, T. A. Dillaha
}

\begin{abstract}
Surface runoff and interflow generated on riparian hillslopes concentrate along rills or topographic depressions as they move downslope. This runoff concentration is an important factor that determines the effectiveness of conservation practices such as vegetated filter strips and riparian buffers and needs to be accounted for while designing such practices. Currently, routinely available DEMs are not detailed enough to capture the runoff concentration that occurs at the hillslope scale. This article investigated the possibility of developing simple relationships that could be used to quantify specific or total contributing areas in terms of hillslope attributes such as slope length or gradient. Riparian hillslopes in the Ridge and Valley region of Virginia were surveyed. The bounds of the survey were defined by the size of dissected hollows and spurs for these hillslopes. Surface elevations were recorded at a resolution of 0.5 to $2 \mathrm{~m}$. Catchment areas which were used as a surrogate for runoff concentration were determined using digital elevation models. Results from this study suggest that although some of the measures of runoff concentration could be expressed in terms of slope length and gradient, it is unlikely that complete probability distribution of catchment areas could be derived based simply on slope gradients and lengths.
\end{abstract}

Keywords. Vegetated filter strips, Runoff concentration, Surface runoff, Interflow, Digital elevation models.

$\mathrm{S}$ urface runoff and shallow subsurface lateral flow (henceforth referred to as interflow) generated on hillslopes in humid headwater catchments typically tend to concentrate along rills, unincised channels, or depressions as they move downslope (Dunne and Black, 1970ab; Anderson and Burt, 1978, Wilson and Dietrich, 1987; Montgomery and Dietrich, 1995). This runoff concentration has been found to adversely affect the effectiveness of conservation practices such as vegetative filter strips (VFS) and riparian buffers which are being widely implemented to control sediment and nutrient losses from agricultural uplands (Dillaha et al., 1986, 1989). Runoff concentration reduces the effectiveness of VFS due to: (a) a decrease in the "effective" area of the VFS exposed to runoff; (b) an increase in runoff velocity due to runoff concentration, and consequently a lesser amount of time available for mechanisms responsible for removal of pollutants to act; and (c) an increase in sediment and pollutant transport capacity associated with increased runoff velocity. At present, existing VFS models either completely neglect runoff concentration (by assuming uniformly distributed flow) or include its effect via an arbitrary reduction factor supplied by the user. Because of the importance of runoff concentration in determining the effectiveness of VFS, there is an increasing need to develop

Article was submitted for publication in May 1999; reviewed and approved for publication by the Soil \& Water Division of ASAE in March 2000.

The authors are Shreeram P. Inamdar, former Doctoral Candidate, and Theo A. Dillaha, ASAE Member Engineer, Professor, Biological Systems Engineering, Seitz Hall, Virginia Tech, Blacksburg, VA 240610303. Corresponding author: Shreeram Inamdar, Environmental Science and Forest Biology, SUNY-ESF, 1 Forestry Drive, Syracuse, NY 13210, phone: 315.470.6950, fax: 315.470.6996, e-mail: <spinamda@syr.edu>. a procedure that can quantify this runoff concentration for a given set of hillslope attributes.

Currently, surface runoff and interflow concentration is quantified by mechanistic and stochastic procedures using digital elevation models (DEMs) based on the assumptions of steady-state runoff and uniform flow generation (Beven and Kirkby, 1979; Lewis et al., 1994). If elevation data are available at the "hillslope scale", DEMs might be the ideal approach for characterizing and quantifying runoff concentration. The "hillslope scale" as defined here, refers to the distance from the hillslope divide to the stream. For example, for riparian slopes in rural watersheds in Virginia this hillslope scale would refer to a slope length distance of 30 to $100 \mathrm{~m}$. At this "hillslope scale", catchment areas that contribute runoff to rills or channels are typically of the order of 10 to $100 \mathrm{~m}^{2}$. To delineate such areas, the resolution of the elevation data required would have to be of the order of $2 \mathrm{~m}$ to $3 \mathrm{~m}$ or less. At present, elevation data that are routinely available from agencies such as the USGS are typically of the resolution of 10 to $30 \mathrm{~m}$. Elevation data with a resolution of 10 to $30 \mathrm{~m}$ will not be able to realistically delineate catchment areas responsible for runoff generation at the "hillslope scale". In the absence of high resolution elevation data ( 2 to $3 \mathrm{~m}$ ) or until such data can be available on a routine basis, alternative procedures for quantifying runoff concentration or delineating catchment areas are needed. One such alternative approach would be to investigate if there are any physical relationships between catchment areas and easily measured hillslope attributes such as slope length and/or gradient. Further, if such relationships did exist, are they robust enough that they could be used to describe the contributing areas and quantify runoff distribution/concentration on hillslopes? The research presented below attempts to answer some of these questions. Such simple relationships, if available, then 
could be used as an aid or guidance tool to account for runoff concentration by conservationists while designing and/or implementing VFS in rural watersheds.

\section{METHODS \\ STUdY Location}

Topographic surveys were performed at four major locations within the Ridge and Valley region of Virginia: Virginia Tech's Whitethorne Experimental Farm in Montgomery County, Virginia Tech's Prices Fork farm in Montgomery County, McDonald's Farm in Montgomery County and Bender Farm in Floyd County. Riparian slopes and landuse within each of the farms are typical of the Ridge and Valley region of Virginia. All the riparian hillslopes surveyed were in pasture or grass cover and were located adjacent to major field drainage ways or first order channels. In terms of slope gradient, a majority of these hillslopes can be classified as moderate (greater than $7 \%$ and less than 20\%) to steep (greater than 20\%). These hillslopes are dissected into distinct topographic forms such as hollows, spurs and/or planar hillslope units. These hillslope forms for the Ridge and Valley Region of Virginia were described in detail by Hack and Goodlett (1960). The length (in the direction of the slope) of these hillslopes from the divide to the stream channels varies between 30 and $100 \mathrm{~m}$. The width (dimension perpendicular to the slope) of the hollows/spurs/planar hillslope units varies from 100 to $300 \mathrm{~m}$ at the stream channel. In addition to the macroscale dissection of these hillslopes into convergent/divergent/planar hillslope units, the soil surface within each of these units is not uniform but is dissected by depressions or drainage channels aligned along the slope.

The boundaries of the topographic surveys on these hillslopes were defined by the size of the convergent/ planar/divergent units into which these slopes are dissected. It is hypothesized that each of these units provides a unique hydrologic response and acts independently of other units. A total of 26 such hillslope units were randomly selected and surveyed. A characterization of these hillslope units in terms of slope gradient and shape is provided in table 1 . The classification of the hillslopes into convergent/planar/divergent forms was based Tsukamoto and Ohta (1988) and determined by visual analysis.

\section{Hillslope Topographic Measurements and ELEVATION INTERPOLATION}

Surface elevation measurements were taken using a TOPCON Total Survey Station that was generally accurate to within $0.001 \mathrm{~m}$ over the surveyed area. Breakpoint

Table 1. Distribution of sampled hillslope gradients and shapes

\begin{tabular}{lc}
\hline Hillslope Attribute & Number of Hillslopes \\
\hline Hillslope gradient (\%) & 14 \\
$0-15$ & 5 \\
$15-20$ & 7 \\
$>25$ & \\
Hillslope shape & 15 \\
Convergent & 8 \\
Planar & 3 \\
Divergent & \\
\hline
\end{tabular}

surface elevations within each hillslope unit were taken at a 0.5 to $2 \mathrm{~m}$ spacing. Where there was a greater variation in the topography, elevations were measured at a spacing of 0.5 to $1.0 \mathrm{~m}$. It was assumed that this resolution was adequate to capture major drainage ways and depressions responsible for subsurface and surface flow concentrations (saturation overland flow as well as infiltration excess overland flow).

Point elevation data collected at a grid resolution of 0.5 to $2 \mathrm{~m}$ were then interpolated to a uniform grid interval of $1 \mathrm{~m}$ using kriging (Linear Variogram Model) using SURFER (Golden Software Inc., 1990). This interpolation was performed for all 26 hillslope surface elevation data sets. Uniformly spaced elevation data generated from SURFER were then used as input in the appropriate format required by the DEM models.

\section{Selection And Use of DEMs to Compute \\ Contributing Areas}

The recently developed Digital Elevation Model Networks (DEMON) was used to compute the specific contributing areas (SCAs) at the foot of the hillslopes (Costa-Cabral and Burges, 1994). SCA $\left(\mathrm{m}^{2} \mathrm{~m}^{-1}\right)$ as computed by DEMON is defined as the contributing area per unit contour length at the foot of the hillslope. The DEMON model was selected because: (a) it is a grid based model, and can accept raster elevation data; (b) flow is generated areally, and not as point sources; (c) flow generated over a cell or pixel is projected downslope over a two dimensional flow strip that allows a realistic treatment of divergent, planar, and convergent topography; (d) flow direction is determined by local aspect angle; and (e) it offers the main advantage of contour based models, i.e., the representation of flow width as a function of local topography. Total contributing areas at the foot of the hillslope were determined using the HECPREPRO (Hellweger, 1999) avenue script model written for ArcView (ESRI, 1998). Input to DEMON and HECPREPRO was provided in raster elevation format with a $1 \mathrm{~m} \times 1 \mathrm{~m}$ cell size. The output from DEMON is a raster file with SCA values corresponding to each cell comprising the hillslope. Out of the total 26 hillslopes surveyed four hillslopes were dropped since the irregularities in the DEMs could not be resolved.

\section{RESULTS AND DISCUSSION}

Considering hillslope shapes, the mean slope gradient for the convergent forms was significantly different than that for the divergent forms at an $\alpha$ level of 0.05 ( $\mathrm{p}=$ 0.002). At the same $\alpha$ level, the difference between the convergent and planar $(\mathrm{p}=0.11)$, and planar and divergent $(\mathrm{p}=0.16)$ hillslope gradients was not significant (table 2$)$. Again, at an $\alpha$ level of 0.05 , slope length for convergent

Table 2. Average slope length and gradient across hillslope shapes

\begin{tabular}{lccc}
\hline & \multicolumn{3}{c}{ Hillslope Shape* } \\
\cline { 2 - 4 } Parameter & Convergent & Divergent & Planar \\
\hline Average slope length $(\mathrm{m})$ & $65.36 \mathrm{a}$ & $42.00 \mathrm{~b}$ & $66.86 \mathrm{~b}$ \\
Average slope gradient $(\mathrm{m} / \mathrm{m})$ & $0.15 \mathrm{a}$ & $0.16 \mathrm{~b}$ & $0.17 \mathrm{~b}$ \\
\hline * Values in a row followed by the same letter are not significantly \\
different.
\end{tabular}




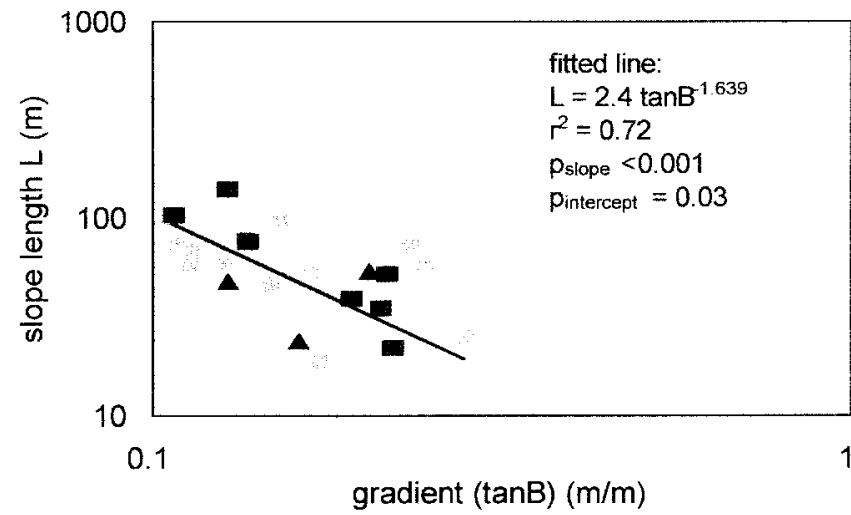

convergent a planar $\Delta$ divergent

Figure 1-Relationship between hillslope lengths and gradients.

slopes was significantly different than that for divergent slopes $(p<0.001)$; whereas, there was no significant difference between convergent and planar $(p=0.10)$ and planar and divergent $(p=0.09)$ slope lengths.

Slope length was inversely related to slope gradient (fig. 1). This result is similar to that reported at catchment scales (Leopold et al., 1992; Montgomery and Dietrich, 1989). A simple least squares regression of log-transformed data with gradient as the independent variable and slope length (fig. 1) as the dependent variable yields:

$$
\begin{gathered}
\mathrm{L}=\lambda \tan \theta^{-1.639} \\
\mathrm{r}^{2}=0.72 ; \quad \mathrm{p}_{\text {slope }}<0.001 ; \quad \mathrm{p}_{\text {intercept }}=0.03
\end{gathered}
$$

where $\lambda=2.4 \mathrm{~m}, \mathrm{~L}$ is the slope length $(\mathrm{m})$, and $\tan \theta$ is the slope gradient $\left(\mathrm{m}^{-1}\right)$. From $\mathrm{p}$ values the regression is significant for both the slope and intercept. Montgomery and Dietrich (1989) reported a length-gradient relationship for source areas contributing to incised channel heads along the main stem of zero order basins in the Tennessee Valley, Marin County, California:

$$
\mathrm{L}=\lambda \tan \theta^{-0.83} \quad \mathrm{r}^{2}=0.47
$$

where $\lambda=67 \mathrm{~m}$. The higher value of the intercept, the lower negative slope value for equation 2 (Montgomery and Dietrich, 1989) as compared to equation 1, reflects the difference in scale and is most likely a consequence of the larger source areas associated with incised channel heads compared to the size of source areas represented by equation 1. In other words, it appears equation 2 represents a higher "threshold" level with respect to source areas compared to equation 1 .

\section{Specific Contributing Areas (SCA)}

There was a wide scatter from minimum to maximum SCA values for a given hillslope gradient, but it was apparent that the degree of scatter decreased from moderate towards steep slope gradients. For moderate slope gradients the distribution of SCAs was comprised of numerous small SCA values $(1>$ SCA > 10), medium sized SCAs $(10>$
SCA > 100), and a few very large SCA values (SCA > 1000). However for steep gradients, the distribution of SCA values was more uniform with most SCA values in the medium range $(100<\mathrm{SCA}<1000)$. In terms of runoff generation, it is likely that a large proportion of the small SCA values (SCA < 10) may or may not contribute runoff. Physically this means that across the width of the hillslope, runoff from steep hillslopes will tend to have a more uniform flow distribution compared to that from moderate slopes. This also means that steeper slopes will have more runoff producing source areas per unit width than mild slopes. SCA was related positively to slope length. Planar and divergent hillslopes were more likely to have smaller SCA values as compared to convergent slope forms (table 3). SCA values for the three hillslope shapes were significantly different $(\mathrm{p}<0.001)$.

To quantify runoff concentration in terms of hillslope length or gradient, it was necessary to determine if any relationship existed between SCA and hillslope length and/or gradient. To investigate this possibility, the maximum SCA value for each hillslope was selected and plotted against its corresponding hillslope length and gradient (figs. 2 and 3, respectively). The maximum SCA value was chosen assuming that if there was any influence of the full slope length or gradient on SCAs it would most likely be manifested at the maximum SCA level. There is a positive relationship between maximum SCA and slope length (fig. 2) and an inverse relationship with respect to slope gradient (fig. 3). These results conform with those previously reported in the literature (Dietrich and Dunne, 1993).

A simple least squares regression of the log-transformed data with maximum SCA as the dependent variable and slope gradient and length as independent variables is given by equations 3 and 4, respectively.

Table 3. Average and maximum SCA values*

\begin{tabular}{lccc}
\hline & \multicolumn{3}{c}{ Hillslope Shape } \\
\cline { 2 - 4 } Parameter & Convergent & Divergent & Planar \\
\hline Average SCA $\left(\mathrm{m}^{2} \mathrm{~m}^{-1}\right)$ & 72 & 43 & 46 \\
$\begin{array}{l}\text { Maximum SCA }\left(\mathrm{m}^{2} \mathrm{~m}^{-1}\right) \\
\begin{array}{l}\text { Average of maximum SCA's } \\
\left(\mathrm{m}^{2} \mathrm{~m}^{-1}\right)\end{array}\end{array}$ & 3583 & 1419 & 400 \\
\hline * SCA values for the three hillslope shapes are significantly different $(\mathrm{p}<$ \\
0.001).
\end{tabular}

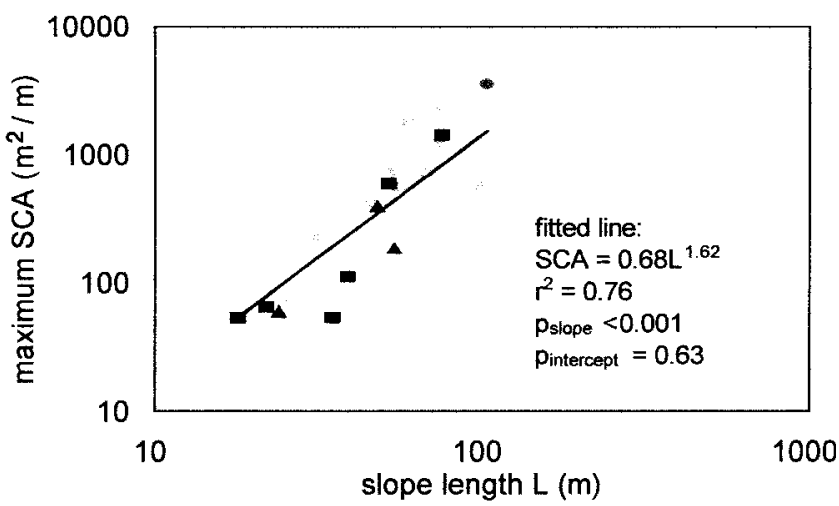

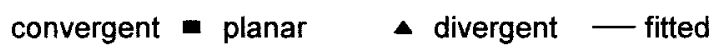

Figure 2-Relationship between SCA and slope length. 


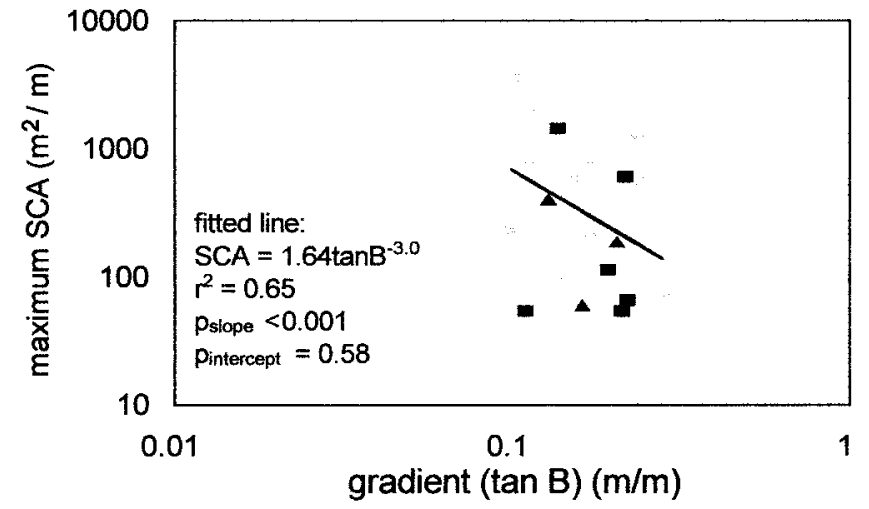

convergent - planar A divergent - fitted

Figure 3-Relationship between SCA and slope gradient.

$$
\begin{gathered}
\mathrm{SCA}=1.64 \tan \theta^{-3.0} \\
\mathrm{r}^{2}=0.65 ; \quad \mathrm{p}_{\text {slope }}<0.001 ; \quad \text { pintercept }=0.58 \\
\mathrm{SCA}=0.68 \mathrm{~L}^{1.62} \\
\mathrm{r}^{2}=0.76 ; \quad \mathrm{p}_{\text {slope }}<0.001 ; \quad \text { pintercept }=0.63
\end{gathered}
$$

In terms of the slope length, equation 4 can be rearranged to give:

$$
\mathrm{L}=1.27 \mathrm{SCA}^{0.62}
$$

From $\mathrm{p}$ values, both equations 3 and 4 indicate a significant relationship with reasonably high regression coefficients. Relationships of this type can provide an initial estimate of the maximum SCA for a hillslope given parameters such as hillslope length or gradient.

Assuming that the maximum SCA for a hillslope can be estimated using equations similar to those above, the next problem is the determination of the probability distribution of SCA values for the hillslope. This problem can be solved if the distribution of SCA values can be quantified and characterized, in terms of the maximum SCA value and the hillslope length and gradient. To investigate this possibility, the populations of SCA values for each hillslope were normalized to the corresponding maximum SCA value (dividing by the maximum value). For each individual hillslope, the population of normalized values were then log-transformed and their mean and variance calculated. The mean value displays a positive relation with slope gradient and an inverse relation with slope length. Simple least squares regressions of these data are:

$$
\begin{gathered}
\mu\left[\ln \left(\mathrm{SCA} / \mathrm{SCA}_{\max }\right)\right]=-4.78+11.42 \tan \theta \\
\mathrm{r}^{2}=0.3 ; \quad \mathrm{p}_{\text {slope }}=0.006 ; \quad \mathrm{p}_{\text {intercept }}<0.001
\end{gathered}
$$

$$
\begin{aligned}
& \mu\left[\ln \left(\mathrm{SCA} / \mathrm{SCA}_{\max }\right)\right]=-1.15-0.03 \mathrm{~L} \\
& \mathrm{r}^{2}=0.50 ; \quad \mathrm{p}_{\text {slope }}<0.001 ; \quad \text { pintercept }=0.011 \\
& \sigma^{2}\left[\ln \left(\mathrm{SCA} / \mathrm{SCA}_{\max }\right)\right]=1.09+0.01 \mathrm{~L} \\
& \mathrm{r}^{2}=0.11 ; \quad \mathrm{p}_{\text {slope }}=0.127 ; \quad \mathrm{p}_{\text {intercept }}=0.012 \\
& \sigma^{2}\left[\ln \left(\mathrm{SCA} / \mathrm{SCA}_{\max }\right)\right]=2.26-3.48 \tan \theta \\
& r^{2}=0.05 ; \quad p_{\text {slope }}=0.28 ; \quad p_{\text {intercept }}<0.01
\end{aligned}
$$

where $\mu_{\left[\ln \left(\mathrm{SCA}_{\mathrm{SCA}}\right)\right]}$ and $\sigma^{2}{ }_{\left[\ln \left(\mathrm{SCA} / \mathrm{SCA}_{\mathrm{max}}\right)\right]}$ are the mean and variance, respectively, of the log-transformed normalized SCA values. Although the regression coefficients are low for nearly all equations, the mean of the sampled distribution has a significant relationship with both, the gradient and the slope length. In contrast, the relationships are not significant for the variance of the sampled distribution. This suggests that although such equations could provide a measure of the mean, their extension to estimate the variance of the distribution of SCA values is suspect.

\section{Total Contributing Areas}

Total contributing areas generated using DEMs for these hillslopes were evaluated using procedures similar to those used for SCAs. The intention here was to determine if there was any relation between contributing areas and hillslope length or gradient. As with SCA, the contributing areas show a positive trend with slope length and an inverse relation with slope gradient.

Using the approach used for the SCA analysis, the maximum contributing areas were plotted against hillslope lengths and gradients (figs. 4 and 5, respectively). A simple least squares regression of contributing areas against slope length is:

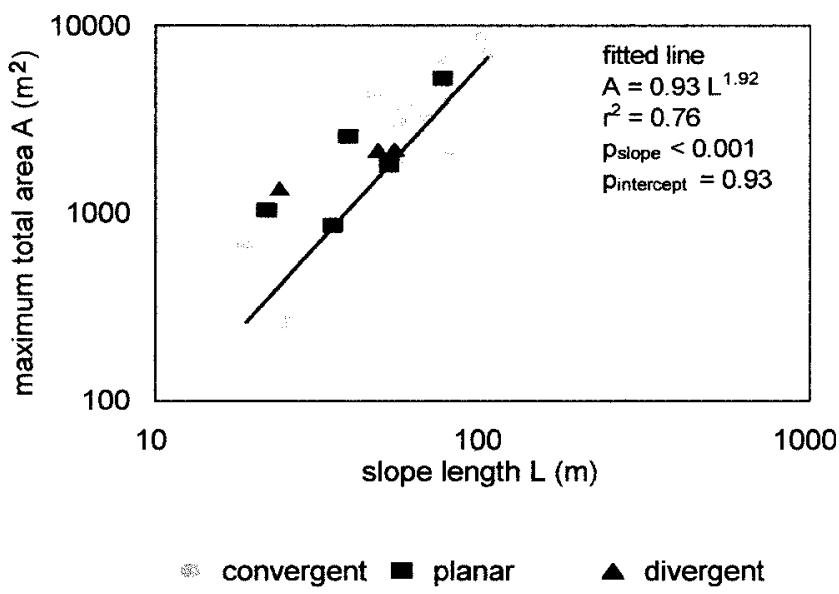

Figure 4-Relationship between total contributing area and slope length. 


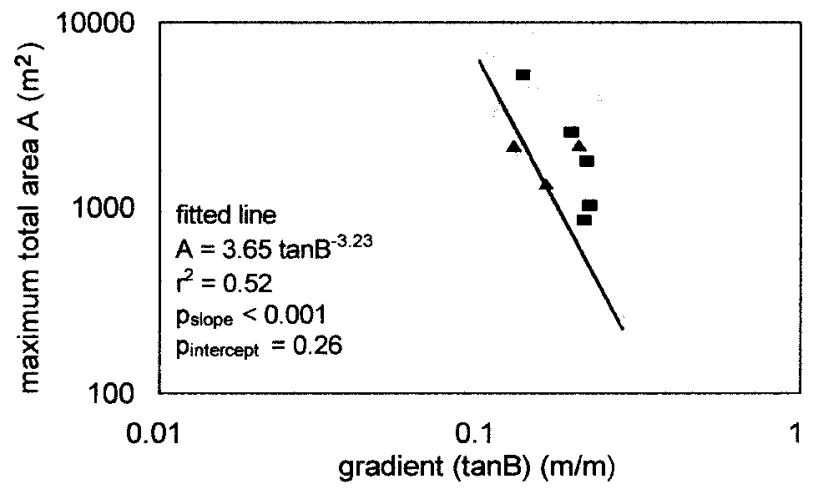

convergent $=$ planar $\quad$ divergent

Figure 5-Relationship between total contributing area and slope gradient.

$$
\begin{gathered}
\mathrm{A}=0.93 \mathrm{~L}^{1.92} \\
\mathrm{r}^{2}=0.76 ; \quad \mathrm{p}_{\text {slope }}<0.001 ; \quad \text { pintercept }=0.93
\end{gathered}
$$

where $A$ is the maximum contributing area $\left(\mathrm{m}^{2}\right)$. In terms of $\mathrm{A}$, the above equation can be rearranged to give:

$$
\mathrm{L}=\lambda \mathrm{A}^{0.53}
$$

where $\lambda=1.03$. Equations similar to those above but at different spatial scales have been reported. Hack (1957) reported a relationship between channel/stream length and drainage area for large drainage networks (watershed scale) in the Shenandoah Valley and adjacent mountains in Virginia:

$$
\mathrm{L}_{\mathrm{c}}=\lambda \mathrm{A}_{\mathrm{d}}^{0.6}
$$

where $\mathrm{L}_{\mathrm{c}}$ is the channel length (miles), $\mathrm{A}_{\mathrm{d}}$ is the drainage area (miles ${ }^{2}$ ), and $\lambda=1$.4. Leopold et al. (1992) added that the exponent used in the above equation is not a constant but varies from one geographic region to another, with values for several regions in the United States falling between 0.6 and 0.7. At a smaller hillslope scale, Montgomery and Dietrich (1989) presented an equation relating channel head source areas and source basin length for hillslopes in the Tennessee Valley, California:

$$
\mathrm{L}=\lambda \mathrm{A}^{0.5}
$$

where $L$ is the source length $(\mathrm{m}), \mathrm{A}$ is the source area $\left(\mathrm{m}^{2}\right)$, and $\lambda=1.48$. A comparison of equations 11 through 13 tends to support the conclusion made by Montgomery and Dietrich (1989) that the exponent in the length-area relationship appears to be scale independent. The influence of scale in these equations (11 through 13) appears to be represented via the constant $\lambda$.
Again, using data collected in our study, maximum contributing areas when expressed in terms of the slope gradient follow the relation:

$$
\begin{gathered}
\mathrm{A}=\beta \tan \theta^{-3.23} \\
\mathrm{r}^{2}=0.52 ; \quad \mathrm{p}_{\text {slope }}<0.001 ; \quad \text { pintercept }=0.26
\end{gathered}
$$

where $\beta=3.65 \mathrm{~m}^{2}$. From $\mathrm{p}_{\text {slope }}$ value the relationship between total area and slope gradient is significant. Montgomery and Dietrich (1989) found the relation between source area and gradient for hillslopes in the Tennessee Valley to be:

$$
\mathrm{A}=\beta \tan \theta^{-1.65} \quad \mathrm{R}^{2}=0.75
$$

where $\beta=1978 \mathrm{~m}^{2}$. In contrast to the close agreement in exponents for equations 11 through 13 , exponents for equations 14 and 15 are considerably different.

\section{Conclusions}

Using specific contributing and total catchment areas as a surrogate of runoff distribution, relationships between catchment areas and hillslope length and gradient were developed. Riparian hillslopes in our study had a significant inverse relationship between slope length and gradient. Maximum SCA values followed a significant positive relationship with slope length and a significant inverse relationship with slope gradient. The mean of the distribution of the normalized SCA values had a significant relationship with slope gradient and length; whereas, the variance of the distribution did not. These results suggest that though the maximum SCA values could be predicted with some confidence for a given set of hillslope length and gradients, it is unlikely that the complete distribution of SCA values could be derived based simply on slope gradients and lengths.

Similar to SCA, total catchment areas had a significant positive relationship with slope and a significant inverse relationship with slope gradient. Interestingly, the exponent in the relation between total catchment areas and slope length for our hillslopes was within the range of values reported at elsewhere for humid headwater catchments. This tends to imply that these regression coefficients may be scale independent. If this implication is confirmed by future studies, this would greatly facilitate the use of such relationships for modeling, since parameters estimated at higher scales could then be extrapolated to lower scales where attributes are difficult to identify and measure.

This article presented an approach to develop simple relationships between catchment areas and easily measured hillslope attributes at a scale for which DEM data are not routinely available. If DEM data at the required resolution are unavailable, such relationships although limited in their predictive ability, can still provide an initial approximate estimate, and could be used as "on-the-field" guidance tool while designing conservation practices. On the other hand, if DEM data of the required resolution are available, it should always be preferred, since application and appropriate interpretation of such data is more likely to provide a more 
representative and definitive picture of runoff concentration. It is also important to note that relationships developed in this article are representative of hillslopes in humid headwater catchments of the Blue Ridge/Piedmont region, and can only be realistically extended for sites with similar climatic and topographic settings.

\section{REFERENCES}

Anderson, M. G., and T. P. Burt. 1978. The role of topography in controlling throughflow generation. Earth Surface Proc. \& Landforms 3: 331-344.

Beven, K., and M. J. Kirkby. 1979. A physically based variable contributing area model of basin hydrology. Hydrol. Sci. Bull. 24: 43-69.

Costa-Cabral, M. C., and S. J. Burges. 1994. Digital Elevation Model Networks (DEMON): A model for flow over hillslopes for computation of contributing and dispersal areas. Water Resour. Res. 30(6): 1681-1692.

Dietrich, W. E., and T. Dunne. 1993. The channel head. In Channel Network Hydrology, eds. K. Beven, and M. J. Kirkby, 175-219. Chichester, U.K.: Wiley.

Dillaha, T. A., R. B. Reneau, S. Mostaghimi, and V. O. Shanoltz. 1989. Vegetative filter strips for nonpoint source pollution control. Transactions of the ASAE 32(2): 491-496.

Dillaha, T. A., J. H. Sherrard, and D. Lee. 1986. Long term effectiveness and maintenance of vegetative filter strips. Virginia Water Resources Research Center. VPI-VWRRCBULL \#153. Blacksburg, Va.: Virginia Tech.

Dunne, T., and R. D. Black. 1970a. An experimental investigation of runoff production in permeable soils. Water Resour. Res. 6 : 478-490.

Dunne, T., and R. D. Black. 1970b. Partial area contributions to storm runoff in a small New England watershed. Water Resour. Res. 6: 1296-1311.

Environmental Systems Research Institute (ESRI) Inc. 1998. ArcView, Ver. 3.1. www.esri.com. Redlands, Calif.

Golden Software Inc. 1990. SURFER for DOS, Ver. 4.15. Golden, Colo.
Hack, J. T. 1957. Studies of longitudinal stream profiles in Virginia and Maryland. U.S. Geol. Survey Prof. Paper 294B, 45-97. Washington, D.C.: USGS.

Hack, J. T., and J. C Goodlett 1960. Geomorphology and forest ecology of a mountain region in the central Appalachians. U.S. Geological Survey Professional Paper 347. Washington, D.C.: USGS.

Hellweger, F. 1999. HECPREPRO. Austin, Tex.: Center for Research in Water Resources, University of Texas at Austin. www.ce.utexas.edu/stu/ferdi/. Austin, Texas.

Lewis, S. M., D. E. Storm, B. J. Barfield, and L. E. Ormsbee. 1994. PRORIL—An erosion model using probability distributions for rill flow and density: I. Model development. Transactions of the ASAE 37(1): 115-123.

Leopold, L. B., M. G. Wolman, and J. P. Miller. 1992. Fluvial Processes in Geomorphology. New York, N.Y: Dover Publications Inc.

Montgomery, D. R., and W. E. Dietrich. 1995. Hydrologic processes in a low-gradient source area. Water Resour. Res. 31(1): 1-10.

Montgomery, D. R., and W. E. Dietrich. 1989. Source areas, drainage density, and channel initiation. Water Resour. Res. 25(8): 1907-1918.

Tsukamoto, Y., and T. Ohta. 1988. Runoff processes on a steep forested hillslope. J. Hydrol. 102: 165-178.

Wilson, C. J., and W. E. Dietrich. 1987. The contribution of bedrock groundwater flow to storm runoff and high pore pressure development in hollows. In Erosion and Sedimentation in the Pacific Rim, Proc. Corvallis Symposium held at Corvallis. IAHS Pub. No. 165. Oxfordshire, UK: Int. Assoc. Hydrological Sciences. 